\title{
SINERGIA
}

REVISTA DO INSTITUTO DE CIÊNCIAS ECONÔMICAS, ADMINISTRATIVAS E CONTÁBEIS (ICEAC)

\section{VALORIZAÇÃO E RECONHECIMENTO DO PROFISSIONAL CONTÁBIL: UMA PERCEPÇÃO DE ALUNOS DE GRADUAÇÃO EM CIÊNCIAS CONTÁBEIS DE UMA UNIVERSIDADE COMUNITÁRIA DE SANTA CATARINA}

\author{
EDUARDA DE SOUZA MANES \\ SABRINA BESEN" \\ ZILTON BARTOLOMEU MARTINS**
}

\begin{abstract}
RESUMO
O objetivo deste artigo foi analisar a percepção de alunos de graduação em Ciências Contábeis de uma universidade comunitária de Santa Catarina acerca da valorização e do reconhecimento do profissional contábil. Esta pesquisa é classificada como quantitativa quanto à abordagem, descritiva em relação aos objetivos e de levantamento no que diz respeito aos procedimentos. Como instrumento de coleta de dados, foi aplicado um questionário contendo 24 questões fechadas, disponibilizado no período de 20 a 30 de agosto de 2019. A população foi de 109 alunos matriculados no curso em 2019/2, e a amostra foi de 86 respondentes, que corresponde a $78,90 \%$ da população. Os dados coletados foram tabulados por meio do software Microsoft Exce/®e a técnica de análise utilizada foi a estatística descritiva, segundo a distribuição de frequência relativa. Como principais resultados, a pesquisa mostrou que grande parte dos alunos possui conhecimento regular em relação ao tema pesquisado. Além disso, concordam, em sua maioria, que o profissional contábil possui importância para a sociedade. Ademais, possui grandes responsabilidades na empresa, mas, por outro lado, ainda possui salário baixo. Também, observou-se que grande parte dos respondentes afirma que a profissão contábil está mais valorizada e com mais oportunidades de trabalho.
\end{abstract}

Palavras-Chave: Valorização. Reconhecimento. Profissional Contábil. Alunos. Ciências Contábeis.

\section{ABSTRACT}

The objective of this article was to analyze the perception of undergraduate students in Accounting at a community university in Santa Catarina about the valuation and recognition of the accounting professional. This research is classified as quantitative in terms of approach, descriptive in relation to objectives and survey with respect to procedures. As a data collection instrument, a questionnaire was applied containing 24 closed questions and made available from 20 to 30 August 2019. The population was 109 students enrolled in the course in 2019/2 and the sample was 86 respondents, who corresponds to $78.90 \%$ of the population. The collected data were tabulated using Microsoft Excel® software and the analysis technique used was descriptive statistics, according to the relative frequency distribution. As main results, the research showed that most students have regular knowledge in relation to the researched topic. Furthermore, they mostly agree that the accounting professional is important to society. In addition, he has great responsibilities in the company, but, on the other hand, still has low wages. It was also observed that most respondents say that the accounting profession is more valued and has more job opportunities.

Keywords: Valuation. Recognition. Accounting Professional. Students. Accounting.

Recebido em: 15-10-2020 Aceito em: 05-01-2021

\section{INTRODUÇÃO}

As primeiras manifestações contábeis apareceram há, aproximadamente, 4.000 a.C., perante a apresentação de registros de renda de templos na baixa Mesopotâmia (KING; CASE; SENECKER, 2017). Desde então, a contabilidade foi evoluindo para se tornar, em nível global, uma prática profissional fundamental no suporte do sistema econômico, em consequência de práticas contábeis utilizadas na geração de informações íntegras que auxiliam nas tomadas de decisões (FEIL, 2016).

Nesse sentido, o Contador tem se destacado como um elemento essencial, principalmente, na elaboração e no controle das informações patrimoniais, pois decisões eficazes tomadas podem levar a

\footnotetext{
Graduada em Ciências Contábeis pela Universidade do Vale do Itajaí (UNIVALI)

"Graduada em Ciências Contábeis pela Universidade do Vale do Itajaí (UNIVALI)

" Doutorando em Administração pela Universidade do Vale do Itajaí (UNIVALI). Mestre em Administração pela Universidade do Vale do Itajaí (UNIVALI). Especialista em Gerência Contábil, Perícia, Auditoria e Controladoria pela Faculdade Internacional de Curitiba (FACINTER). Graduado em Ciências Contábeis pela Universidade do Vale do Itajaí (UNIVALI). Docente do curso de Ciências Contábeis na Universidade do Vale do Itajaí (UNIVALI). E-mail: ziltonmartins@univali.br
} 
empresa a ganhos de mercado, a redução de custos, entre outros. Porém, quando a ação é equivocada, pode incorrer em endividamento e comprometer gravemente seu patrimônio. Assim sendo, confirma-se o quão importante é a contabilidade, cujas informações precisam ser as mais confiáveis possíveis (MIRANDA; FARIA, 2016).

Anteriormente, Fahl e Manhani (2015) já mencionavam que a busca pela atualização dos conhecimentos e a procura por novos desafios deve ser constante para o Contador. Na nova realidade empresarial que se apresenta, esses profissionais precisam ser mais competitivos e ter o desejo de prestar novos serviços, preocupados com a qualidade oferecida.

Dessa forma, Virtuoso e Martins (2018) enfatizam que, para o Contador atingir o nível de reconhecimento necessário, há um longo caminho a percorrer, isto é, o de ser reconhecido como profissional fundamental para as organizações. Nesse contexto, Franco et al. (2018) afirmam que a capacidade de comunicação, juntamente com técnicas de marketing, contribuem para a valorização do profissional e para a obtenção de novas conquistas, uma vez que o mercado contábil é competitivo e dispõe de uma classe que atua de modo independente.

Diante do exposto, questiona-se: qual a percepção de alunos de graduação em Ciências Contábeis de uma universidade comunitária de Santa Catarina acerca da valorização e reconhecimento do profissional contábil? Assim, o objetivo deste artigo é analisar a percepção de alunos de graduação em Ciências Contábeis de uma universidade comunitária de Santa Catarina acerca da valorização e do reconhecimento do profissional contábil.

Como justificativa teórica, Cernusca e Balaciu (2015) analisaram a percepção dos estudantes de Ciências Contábeis sobre a imagem do Contador e a profissão contábil e propõem estender o estudo, expandindo o grupo-alvo com os alunos de contabilidade de outras universidades do exterior. Além disso, Almeida e Medeiros (2017) compreenderam como o Contador, atualmente, é percebido pelo discente de Ciências Contábeis e recomendam novos estudos para que se possa compreender como aumentar a percepção do profissional contábil enquanto líder, comunicador. Por fim, Moraes e Martins (2018) analisaram a percepção dos discentes de administração acerca dos profissionais contábeis e sugerem realizar uma pesquisa com os futuros (as) Contadores (as) para identificar a percepção que possuem a respeito da profissão contábil.

Este artigo se justifica empiricamente, na medida em que se deseja estudar a valorização e o reconhecimento que o profissional contábil possui, tornando-se relevante para sanar possíveis dúvidas que os futuros (as) alunos (as) do curso de Ciências Contábeis possuem para a escolha desta profissão, contribuindo para um melhor entendimento da opção pelo campo da contabilidade. Ainda convém lembrar que este estudo pretende conhecer a opinião dos acadêmicos sobre esta percepção, e, juntamente, contribuir com as instituições de ensino com o propósito de esclarecer o entendimento dos acadêmicos sobre a valorização e reconhecimento de sua futura profissão. Além disso, a pesquisa visa contribuir com os profissionais contábeis, com o intuito de serem cada vez mais valorizados e reconhecidos pela atividade que exercem.

Este trabalho contém, além desta introdução, a fundamentação teórica sobre o tema, os procedimentos metodológicos utilizados para a realização deste artigo, a análise dos resultados e, por fim, as considerações finais e as referências deste estudo.

\section{FUNDAMENTAÇÃO TEÓRICA}

A fundamentação teórica deste trabalho é dividida em: profissão contábil, valorização e reconhecimento do profissional contábil e estudos anteriores sobre o tema.

\subsection{A Profissão Contábil}

No Brasil, entende-se que a primeira função, na área da contabilidade, a ser reconhecida foi a de guarda-livros, umas das primeiras profissões liberais permitidas em solo nacional. No Brasil, foi por meio do Decreto Imperial no 4.475 , do ano de 1870, que surgiu a contabilidade. Com isso, mediante a regulamentação da profissão de guarda-livros, a profissão foi se desenvolvendo até chegar ao curso superior, que ficou conhecido como Ciências Contábeis (CAVALCANTE, 2012).

A profissão contábil só passou a ter uma evolução no Brasil, aproximadamente, no ano de 1945, quando houve a publicação do Decreto-Lei no 9.295, que criou o Conselho Federal de Contabilidade e determinou a exigência para o exercício da profissão contábil (PAULA, 2016). Além disso, equiparando-se com outras profissões, como, por exemplo, Direito, Medicina e Engenharia, a profissão contábil nem sempre foi vista como atividade de destaque. Ainda é importante relatar que esta profissão é cercada de estereótipos e mitos, incluindo a atividade do profissional e o profissional em si (MIRANDA; MIRANDA; ARAÚJO, 2013).

$\mathrm{Na}$ mesma concepção, Cernusca e Balaciu (2015) apontam que a profissão contábil está em 
concorrência com outras profissões. Em função disso, é importante analisar como a imagem da profissão é percebida na sociedade, quais os desafios e perspectivas futuras que ela enfrenta. Os Contadores apresentam evidências sobre a existência e a necessidade da profissão contábil nas atividades de todas as organizações, mas também como a imagem desta profissão, no mundo, é determinada pelo nível de conhecimento das pessoas que a utilizam (MARIN, 2018).

É evidente que a escolha pela profissão contábil é desafiadora e com obstáculos, mas que o mercado de trabalho sabe da necessidade deste profissional e o quanto sua atuação exerce influência no desenvolvimento, crescimento e andamento das organizações (MACHADO; ROSA; MARTINS, 2019). Na visão de Cavalcante (2012), a atuação da Contabilidade é de suma importância, pois visa ao desenvolvimento e à sobrevivência das organizações. Não havendo contabilidade, iria ser praticamente impossível existir um controle referente aos recursos privados e públicos, ou seja, dificilmente, seria possível avaliar a viabilidade econômica e financeira das entidades.

De forma mais abrangente, o profissional da área contábil possui grande responsabilidade e executa diversas funções que vão desde o controle financeiro até a elaboração das demonstrações contábeis e sua análise na realização de consultorias e auditorias (SILVA; SANTANA; MEIRELLES JÚNIOR, 2017). A profissão contábil é, sem dúvida, uma das que mais exige atualização e adaptação às mudanças por parte de seus profissionais (AYRES; NASCIMENTO; MACEDO, 2017). Além do mais, Silva, Santana e Meirelles Júnior (2017) complementam que o Contador também precisa ter conhecimento avançado em informática, saber outros idiomas, ter uma linguagem diferenciada e moderna, ser ético, cumprir as exigências legais, ser prático e objetivo.

Corroborando com o parágrafo anterior, Machado, Rosa e Martins (2019) salientam que é necessário o profissional contábil estar em constante atualização, visto que o mercado de trabalho demonstra buscar profissionais com capacidade técnica e, também, com capacidades que gerem ações e soluções, procurando, dessa forma, profissionais desenvolvidos, ou seja, é preciso sempre investir nas atividades e ações que agreguem conhecimento e melhores procedimentos para encarar os obstáculos da profissão. Um papel importante do Contador é representado pelas habilidades necessárias para desenvolver as atividades dentro da profissão contábil (CERNUSCA; BALACIU, 2015).

\subsection{Valorização e Reconhecimento do Profissional Contábil}

Na visão de Reis et al. (2015), devido à aderência às Normas Internacionais de Contabilidade (IFRS), a imagem do profissional contábil acabou sendo modificada, uma vez que passou a ser visto como "oportunidade de negócio", deixando a imagem relacionada ao cumprimento, apenas, das obrigações acessórias para a imagem de participante ativo nos processos gerenciais, que resultou na exigência da formação do profissional. Segundo os autores, foi imprescindível que esses profissionais buscassem qualificação com a intenção de procurarem novos conhecimentos, técnicas e habilidades devido às exigências do mercado, diante da realidade das organizações.

Comparando com períodos anteriores, a profissão contábil está mais valorizada, e o mercado de trabalho tem o conhecimento da necessidade de seus serviços prestados. Porém, é necessário que o profissional esteja sempre atualizado, fazendo cursos que agreguem conhecimentos, tendo mais técnicas para enfrentar os obstáculos da profissão, pois o mercado de trabalho quer profissionais competentes e com habilidades, com alto nível de preparo (MACHADO; ROSA; MARTINS, 2019).

Com isso, Franco et al. (2018) salientam que o mercado contábil é competitivo e possui uma classe que atua de forma independente. Assim, a capacidade de comunicação do profissional e a ética são fatores que contribuem para a valorização da profissão. Em complemento, Moraes e Martins (2018) abordam que a confiabilidade nas informações, geradas pela contabilidade para o processo decisório dos gestores, é um importante fator para a valorização da profissão contábil. Nesse sentido, Raffaelli, Espejo e Portulhak (2016) já afirmavam que a valorização da profissão contábil é um fator relevante para que os usuários da informação contábil, sejam eles internos ou externos à organização, atribuam confiabilidade às informações a eles destinadas, que, também, pode influenciar o relacionamento entre entidade e seu ambiente na busca da eficiência dentro das organizações.

Na mesma perspectiva, Fahl e Manhani (2015) já enfatizavam que a contabilidade tende a acompanhar a evolução das empresas, e o profissional contábil é um dos principais atores que faz parte deste cenário. Portanto, o Contador deve cumprir bem o seu papel e ter o reconhecimento que merece, que esteja à altura de sua importância. Dessa forma, a tendência é que sejam adotadas várias ações para a valorização deste profissional, para melhorar sua capacitação, preparando-o não só para atuar de forma diferenciada, mais sim para capacitá-lo a orientar futuras gerações.

Os autores supracitados complementam que, para a profissão ser respeitada, os profissionais devem dar a devida importância ao trabalho que desenvolvem, seja no setor privado, público, seja na educação. Ressalta-se que o profissional contábil é um agente de constantes mudanças, deve apresentar suas 
habilidades e, além disso, valorizar os serviços que presta. Além do mais, o Contador também contribui para o crescimento e para a continuidade da empresa, já que ele é quem conhece o funcionamento e a sistemática da mesma, uma vez que registra os fatos que acontecem em todos os departamentos.

Raffaelli, Espejo e Portulhak (2016) dizem que os futuros economistas, além de reconhecer a importância e a complexidade do trabalho destes profissionais, assentam confiança nos contabilistas e ressaltam que a imagem formada pelos estudantes de Ciências Contábeis favorece a confiabilidade dos futuros economistas nas informações contábeis. Por outro lado, Cernusca e Balaciu (2015) possuem uma visão diferente, uma vez que afirmam que o público em geral não percebe o verdadeiro valor da profissão contábil e do Contador. Assim, os órgãos profissionais possuem um papel fundamental e contribuem, permanentemente, para melhorar a imagem da profissão contábil, de modo que o Contador não tenha um papel marginal na sociedade.

Nesse contexto, o Conselho Federal de Contabilidade (CFC), na condição de órgão regulador da profissão no País, também emitiu, ao longo dos últimos anos, diversas regulamentações relacionadas à Educação Profissional Continuada (EPC). A EPC é o meio pelo qual o profissional se encontra em constante atualização, estando relacionada à qualidade dos serviços prestados, com isso, visa à valorização da profissão (MORAIS; MARTINS; ALBERTON, 2017). Mendonça e Martins (2020) complementam que a educação representa um processo incessante e interminável que exige com que o profissional tenha capacidade cognitiva para melhorar sua função e desenvolver um nível diferenciado como forma de valorização do trabalho e, por consequência, da profissão.

Cabe destacar que, anteriormente, Miranda, Miranda e Araújo (2013) já salientavam que, muitas vezes, a sociedade não possui reconhecimento em relação ao profissional contábil devido a alguns aspectos que envolvem a área, tais como, os serviços burocráticos ligados à prestação de contas com o domínio governamental e órgãos tributários. Desse modo, quanto maior for a procura pelos serviços contábeis e com o reconhecimento do valor que a informação contábil agrega às entidades, gradativamente, este profissional será valorizado por todos os usuários das informações por ele desenvolvidas (MACHADO; ROSA; MARTINS, 2019).

Na visão de Ayres, Nascimento e Macedo (2017), uma forma do profissional atingir satisfação pela sua carreira é ser reconhecido e valorizado profissionalmente. A profissão contábil está sendo vista em crescimento e seu desenvolvimento é contínuo, ou seja, vem se tornando bastante reconhecida e valorizada. Desse modo, essas características acabam se tornando indispensáveis para o atuante da profissão, para sentir-se preparado e qualificado e ser encorajado a novos obstáculos, já que a confiança é capaz de influenciar na melhora desses processos e, por consequência, da satisfação profissional.

\subsection{Estudos Anteriores sobre o Tema}

No Quadro 1, apresentam-se alguns estudos sobre o tema selecionados na literatura, identificando autores, objetivos e principais resultados. Cabe evidenciar que esses trabalhos foram obtidos por meio do Google Acadêmico e das bases Spell e Portal de Periódicos Capes, com a utilização de palavras-chave "valorização profissional contábil e "reconhecimento profissional contábil".

Quadro 1 - Estudos anteriores sobre o tema

\begin{tabular}{|c|c|c|}
\hline Autores & Objetivos & Principais Resultados \\
\hline $\begin{array}{c}\text { Cavalcante } \\
\text { (2012) }\end{array}$ & $\begin{array}{l}\text { Identificar a percepção dos alunos } \\
\text { iniciantes do curso de Ciências } \\
\text { Contábeis de uma faculdade do } \\
\text { extremo oeste de Santa Catarina } \\
\text { sobre as atividades realizadas na } \\
\text { profissão contábil e também, sobre as } \\
\text { perspectivas da profissão. }\end{array}$ & $\begin{array}{l}\text { Verificou-se que a visão do acadêmico sobre a profissão contábil } \\
\text { ganha amplitude na medida em que conclui o curso. Observa-se } \\
\text { a necessidade de os acadêmicos serem mais conhecedores da } \\
\text { profissão escolhida. É importante divulgar o valor desta profissão } \\
\text { na sociedade, visando mudar a imagem que muitos possuem do } \\
\text { Contador. Da mesma forma, é relevante demonstrar a função } \\
\text { gerencial do profissional, bem mais ampla do que os simples } \\
\text { registros contábeis. }\end{array}$ \\
\hline $\begin{array}{l}\text { Miranda, } \\
\text { Miranda e } \\
\text { Araújo } \\
(2013)\end{array}$ & $\begin{array}{l}\text { Analisar a percepção dos estudantes } \\
\text { do ensino médio com relação à } \\
\text { profissão contábil e à formação do } \\
\text { Contador. }\end{array}$ & $\begin{array}{l}\text { Os resultados obtidos demonstram que certas situações } \\
\text { relacionadas à profissão ainda são desconhecidas, e alguns } \\
\text { mitos e estereótipos apontados pelos estudos internacionais } \\
\text { foram encontrados na amostra analisada. }\end{array}$ \\
\hline
\end{tabular}




\begin{tabular}{|c|c|c|}
\hline Autores & Objetivos & \begin{tabular}{|l|} 
Principais Resultados \\
\end{tabular} \\
\hline $\begin{array}{l}\text { Farber et al. } \\
\text { (2014) }\end{array}$ & $\begin{array}{l}\text { Descrever a percepção dos alunos do } \\
\text { curso de Ciências Contábeis sobre a } \\
\text { profissão para a qual se preparam. }\end{array}$ & $\begin{array}{l}\text { É necessário mostrar a importância do trabalho do profissional da } \\
\text { contabilidade, valorizando a classe, pois ainda há acadêmicos } \\
\text { que não conhecem realmente a profissão escolhida. Tanto a } \\
\text { sociedade quanto os próprios estudantes precisam corrigir a } \\
\text { imagem que possuem do profissional da contabilidade, } \\
\text { separando-o do papel do burocrata. É necessário admitir que as } \\
\text { Ciências Contábeis enobreçam o indivíduo que faz uso de suas } \\
\text { ferramentas, dando-lhe competências para auxiliar as manobras } \\
\text { empresariais. }\end{array}$ \\
\hline $\begin{array}{c}\text { Cernusca e } \\
\text { Balaciu } \\
(2015)\end{array}$ & $\begin{array}{l}\text { Apresentar a percepção dos } \\
\text { estudantes de Ciências Contábeis } \\
\text { sobre a imagem do Contador e a } \\
\text { profissão contábil. }\end{array}$ & $\begin{array}{l}\text { Os Contadores possuem uma percepção bem definida sobre a } \\
\text { imagem da profissão contábil e sobre a imagem do Contador, } \\
\text { tanto no contexto atual quanto nas perspectivas futuras. Os } \\
\text { alunos pesquisados estão preocupados com a profissão contábil } \\
\text { e com a imagem que o Contador possui na sociedade; percebem } \\
\text { que o público, em geral, não conhece o verdadeiro valor da } \\
\text { profissão contábil e do trabalho de Contador. }\end{array}$ \\
\hline $\begin{array}{l}\text { Raffaelli, } \\
\text { Espejo e } \\
\text { Portulhak } \\
\text { (2016) }\end{array}$ & 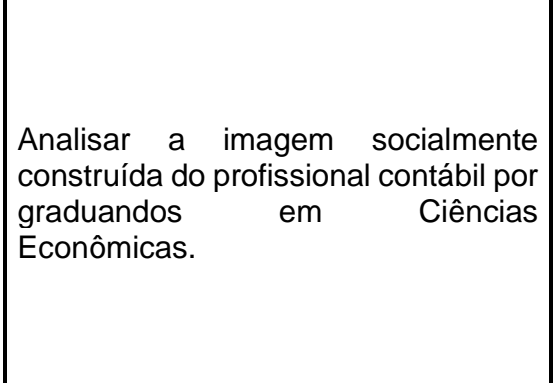 & $\begin{array}{l}\text { Os futuros economistas depositam confiança nos contabilistas, } \\
\text { além de reconhecer a importância e complexidade do trabalho } \\
\text { destes profissionais. É necessário que os profissionais de } \\
\text { contabilidade tenham conhecimento de como são vistos pelos } \\
\text { futuros economistas, considerando o papel desses últimos no } \\
\text { ambiente de atuação dos primeiros. E seu trabalho, para ser } \\
\text { adequadamente valorizado, precisa transmitir uma imagem } \\
\text { positiva, o que implica ressaltar as percepções positivas e mitigar } \\
\text { possíveis efeitos negativos de determinadas percepções que } \\
\text { desvalorizem a atividade e os profissionais de contabilidade. }\end{array}$ \\
\hline Paula (2016) & $\begin{array}{|llr|}\text { Fomentar } \quad \text { o debate sobre } & \text { a } \\
\text { importância da ciência contábil, no } \\
\text { campo da contabilidade aplicada ao } \\
\text { setor público e a valorização dos } \\
\text { profissionais da contabilidade nas } \\
\text { entidades públicas. }\end{array}$ & $\begin{array}{l}\text { Os profissionais estão sendo valorizados em sua carreira no que } \\
\text { tange aos procedimentos e às responsabilidades, mas, por outro } \\
\text { lado, no que se refere aos reconhecimentos remuneratórios, os } \\
\text { mesmos ainda não estão sendo valorizados, principalmente, pela } \\
\text { ausência de plano de carreira próprio. }\end{array}$ \\
\hline $\begin{array}{l}\text { Cunha, } \\
\text { Olivio e } \\
\text { Martins } \\
(2017)\end{array}$ & $\begin{array}{l}\text { Descrever a percepção dos } \\
\text { empresários acerca do grau de } \\
\text { importância e nível de satisfação dos } \\
\text { serviços prestados pelo profissional } \\
\text { da contabilidade. }\end{array}$ & $\begin{array}{l}\text { Os clientes atribuem maior importância para a apuração de } \\
\text { impostos e confecção de folha de pagamento. Já os serviços de } \\
\text { assessoria para a gestão da empresa e geração dos } \\
\text { demonstrativos contábeis são considerados de menor } \\
\text { importância. Com relação ao nível de satisfação, os clientes estão } \\
\text { entre "satisfeitos" e "muito satisfeitos" em relação à maior parte } \\
\text { dos serviços prestados pelos profissionais da contabilidade. }\end{array}$ \\
\hline $\begin{array}{l}\text { Parker e } \\
\text { Warren } \\
\text { (2017) }\end{array}$ & $\begin{array}{l}\text { Pesquisar os valores de carreira dos } \\
\text { papéis dos profissionais contábeis em } \\
\text { sua apresentação e o valor da } \\
\text { identidade profissional. }\end{array}$ & $\begin{array}{l}\text { Os Contadores empregam uma série de estratégias de } \\
\text { dramatização no local de trabalho, bem como idealização e } \\
\text { estratégias de mistificação dentro e além do local de trabalho, } \\
\text { para reconstruir identidades profissionais em face do que eles } \\
\text { veem ser o persistente e indesejável estereótipo contábil. }\end{array}$ \\
\hline $\begin{array}{l}\text { Almeida e } \\
\text { Medeiros } \\
(2017)\end{array}$ & $\begin{array}{l}\text { Compreender como o Contador, } \\
\text { atualmente, é percebido pelos } \\
\text { discentes de Ciências Contábeis e } \\
\text { avaliar se há diferentes percepções } \\
\text { entre ingressantes e concluintes. }\end{array}$ & $\begin{array}{l}\text { Uma parcela dos respondentes atribuiu o termo ético como a } \\
\text { característica positiva mais frequente para o Contador. } \\
\text { Contrariamente, outra parcela acredita que a falta de ética é o } \\
\text { atributo negativo que melhor expressa alguns representantes } \\
\text { dessa profissão, na contemporaneidade. }\end{array}$ \\
\hline $\begin{array}{l}\text { Ayres, } \\
\text { Nascimento } \\
\text { e Macedo } \\
\text { (2017) }\end{array}$ & $\begin{array}{l}\text { Avaliar a satisfação quanto à } \\
\text { Qualidade de Vida no Trabalho - QVT } \\
\text { do profissional de contabilidade. }\end{array}$ & $\begin{array}{l}\text { Os profissionais buscam, acima de tudo, o sentimento de } \\
\text { valorização profissional, por meio de compensação adequada, de } \\
\text { aplicação de regras justas, de oportunidades de crescimento, de } \\
\text { uso de sua capacidade e de melhores condições de trabalho. } \\
\text { Concluiu-se, também, que as mulheres se sentem menos } \\
\text { integradas socialmente, assim como os profissionais que atuam } \\
\text { na iniciativa privada. }\end{array}$ \\
\hline
\end{tabular}




\begin{tabular}{|c|c|c|}
\hline Autores & Objetivos & Principais Resultados \\
\hline $\begin{array}{l}\text { Silva, } \\
\text { Santana e } \\
\text { Meirelles } \\
\text { Júnior } \\
(2017)\end{array}$ & $\begin{array}{l}\text { Descrever a percepção de alunos do } \\
\text { curso de Ciências Contábeis de uma } \\
\text { IES quanto à formação acadêmica e } \\
\text { à preparação profissional oferecida } \\
\text { pela instituição para ingressar no } \\
\text { mercado de trabalho. }\end{array}$ & $\begin{array}{l}\text { Os alunos, em sua maioria, acreditam que o mercado exige um } \\
\text { profissional que, constantemente, se atualize. Também, foi } \\
\text { encontrado certo nível de concordância parcial quanto à } \\
\text { aquisição de competências necessárias para ingressar e atuar no } \\
\text { mercado durante o curso. }\end{array}$ \\
\hline $\begin{array}{l}\text { Moraes e } \\
\text { Martins } \\
(2018)\end{array}$ & $\begin{array}{l}\text { Analisar a percepção dos discentes } \\
\text { de Administração acerca dos } \\
\text { profissionais contábeis. }\end{array}$ & $\begin{array}{l}\text { Os discentes de Administração atribuem grande importância ao } \\
\text { profissional contábil. O conhecimento da área contábil contribui } \\
\text { para o desenvolvimento profissional. E as informações geradas } \\
\text { pelo profissional contábil são uma importante ferramenta no } \\
\text { processo decisório para os gestores. Os discentes também } \\
\text { acreditam que essas informações devem possuir, como } \\
\text { característica essencial, a confiabilidade. }\end{array}$ \\
\hline Marin (2018) & $\begin{array}{l}\text { Identificar o papel e a importância de } \\
\text { profissionais contábeis em qualquer } \\
\text { entidade econômica. }\end{array}$ & $\begin{array}{l}\text { A pesquisa revelou a importância dos contabilistas na atividade } \\
\text { das entidades econômicas. A imagem desta profissão, no mundo, } \\
\text { é determinada pelo nível de formação das pessoas que } \\
\text { participam do estudo, em grau significativo, bem como pelo modo } \\
\text { de treinamento da contabilidade como futuro profissional. }\end{array}$ \\
\hline $\begin{array}{l}\text { Virtuoso e } \\
\text { Martins } \\
(2018)\end{array}$ & $\begin{array}{l}\text { Analisar a percepção dos } \\
\text { empresários sobre a evolução do } \\
\text { perfil do Contador. }\end{array}$ & $\begin{array}{l}\text { Os empresários percebem a evolução no perfil do profissional } \\
\text { contábil, consideram-no essencial para os negócios. A escrita } \\
\text { contábil não seria mantida se não fossem obrigados. }\end{array}$ \\
\hline $\begin{array}{l}\text { Machado, } \\
\text { Rosa e } \\
\text { Martins } \\
(2019)\end{array}$ & $\begin{array}{l}\text { Analisar a percepção dos } \\
\text { profissionais contábeis acerca do } \\
\text { mercado de trabalho. }\end{array}$ & $\begin{array}{l}\text { Os profissionais contábeis devem estar preparados para atender } \\
\text { às exigências do mercado, se esforçando para acompanhar as } \\
\text { mudanças ocorridas nas áreas da contabilidade e, sempre, se } \\
\text { atualizando para o cumprimento das obrigatoriedades. }\end{array}$ \\
\hline
\end{tabular}

Fonte: Elaborado pelos Autores (2020)

Com base no Quadro 1, percebe-se que os serviços prestados pelo profissional contábil são de extrema importância, tanto para os empresários quanto para as entidades econômicas. Entretanto, é fundamental transparecer essa importância, valorizando e reconhecendo a classe, pois existem acadêmicos que não conhecem totalmente a profissão escolhida. As pesquisas, também, revelaram que este profissional possui valorização por parte dos alunos e empresários e, dessa forma, o Contador deve estar em atualização e qualifiçação constantes sobre a legislação que regulamenta os serviços prestados por este profissional. Ressaltam-se, também, os estudos internacionais apresentados, destacando para o valor do Contador nas entidades econômicas e para a valorização dos alunos com a profissão contábil pelo mundo.

\section{PROCEDIMENTOS METODOLÓGICOS}

Este estudo, quanto à abordagem do problema, é categorizado como uma pesquisa quantitativa, a qual possui características de demonstrar opiniões e informações em números para classificação e análise, ou seja, requer o uso de recursos e de técnicas estatísticas (PRODANOV; FREITAS, 2013). Na mesma concepção, Richardson (2017) descreve a pesquisa quantitativa como um meio para avaliar teorias objetivas, analisando a relação entre as variáveis. Quanto aos objetivos da pesquisa, a mesma é classificada como descritiva, pois busca observar, registrar, analisar e interpretar os acontecimentos, utilizando-se de práticas padronizadas de coleta de dados, como, por exemplo, o questionário e a análise sistemática (RODRIGUES et al., 2014).

Com relação aos procedimentos, esta é uma pesquisa de levantamento devido à obtenção dos dados em decorrência de um questionário. A pesquisa abrange perguntas diretas para as pessoas, com o intuito do que se deseja conhecer e, por meio de análise quantitativa, obtêm-se as conclusões dos dados coletados (RODRIGUES et al., 2014). Nesse sentido, a pesquisa de levantamento baseia-se na coleta de dados referentes a uma determinada população a partir da amostra obtida, de forma clara e direta com o objetivo de saber o comportamento (SILVA, 2017).

Como instrumento de coleta de dados, foi utilizado um questionário baseado nos estudos de Cavalcante (2012), Miranda, Miranda e Araújo (2013), Moraes e Martins (2018) e Machado, Rosa e Martins (2019), contendo 24 (vinte e quatro) questões fechadas e validado por quatro professores da área. Destaca-se que os quatro professores são mestres e lecionam no curso, objeto deste estudo. Eles analisaram o instrumento com o intuito de observar possíveis incoerências nas questões e se estavam atreladas ao objetivo deste artigo. Dessa forma, apontaram as melhorias a serem feitas no questionário e devolveram aos autores, os quais acataram todas as recomendações propostas. Ressalta-se que o mesmo foi aplicado de forma impressa, no período de 20 a 30 de agosto de 2019. 
Conforme Richardson (2017), pode-se definir população quando se refere a todos os habitantes de determinado lugar, ou seja, é o conjunto de elementos que possuem determinadas características, enquanto amostra é definida como todo subconjunto do conjunto da população. Nesse contexto, a população analisada foi formada por 109 (cento e nove) discentes matriculados no curso de Ciências Contábeis de uma universidade comunitária de Santa Catarina, em 2019/2.

Tratando-se de amostra, Prodanov e Freitas (2013) salientam que é uma pequena parte dos elementos que compõem a população. Nesse contexto, foram recebidos 91 (noventa e um) questionários respondidos, entretanto 5 (cinco) destes tiveram que ser invalidados por conta de erros de preenchimento. Com isso, alcançou-se uma amostra de 86 (oitenta e seis) respondentes, que representa $78,90 \%$ da população. A tabulação dos dados ocorreu por meio do software Microsoft Exce/ $\Theta$, e a técnica de análise de dados utilizada foi a estatística descritiva, segundo a distribuição de frequência relativa.

\section{ANÁLISE DOS RESULTADOS}

A análise dos resultados foi dividida em quatro etapas. Na primeira, buscou-se identificar o perfil dos respondentes; na segunda, a percepção dos alunos quanto à profissão contábil; na terceira, a percepção dos alunos quanto à valorização e reconhecimento do profissional contábil e, na quarta etapa, buscou-se identificar as exigências do mercado de trabalho para os profissionais contábeis. Para caracterização da amostra da pesquisa, foram efetuados alguns questionamentos que permitissem uma prévia identificação dos respondentes, conforme são apresentados nas Tabelas 1 a 4. Nesse contexto, a Tabela 1 apresenta o gênero dos respondentes.

Tabela 1 - Gênero

\begin{tabular}{lc} 
Gênero & Frequência Relativa \\
\hline Masculino & $55,81 \%$ \\
\hline Feminino & $44,19 \%$ \\
\hline Total & $\mathbf{1 0 0 , 0 0 \%}$
\end{tabular}

Fonte: Dados da Pesquisa (2020)

É possível verificar um equilíbrio no gênero dos respondentes, com destaque para o masculino, que representa $55,81 \%$ da amostra. A Tabela 2 evidencia a idade dos alunos do curso de graduação em Ciências Contábeis.

Tabela 2 - Idade

\begin{tabular}{lc}
\hline Idade & Frequência Relativa \\
\hline Até 20 anos & $37,21 \%$ \\
\hline De 21 a 24 anos & $37,21 \%$ \\
\hline De 25 a 28 anos & $10,47 \%$ \\
\hline De 29 a 32 anos & $5,81 \%$ \\
\hline De 33 a 36 anos & $4,65 \%$ \\
\hline De 37 a 40 anos & $4,65 \%$ \\
\hline De 41 a 44 anos & $0,00 \%$ \\
\hline Acima de 44 anos & $0,00 \%$ \\
\hline Total & $\mathbf{1 0 0 , 0 0 \%}$
\end{tabular}

Fonte: Dados da Pesquisa (2020)

Observa-se que a grande maioria dos acadêmicos $(74,42 \%)$ possui idade até 24 anos, revelando que há predominância de jovens no curso pesquisado. Na Tabela 3, é possível identificar qual período do curso os discentes estão matriculados.

Tabela 3 - Período

\begin{tabular}{|c|c|}
\hline Períndo & Freauência Relativa \\
\hline 1 a período & $13,95 \%$ \\
\hline $2^{a}$ período & $13,95 \%$ \\
\hline $3^{a}$ período & $5,81 \%$ \\
\hline $4^{a}$ período & $16,28 \%$ \\
\hline $5^{\mathrm{a}}$ período & $6,98 \%$ \\
\hline $6^{a}$ período & $8,14 \%$ \\
\hline 7ª período & $10,47 \%$ \\
\hline $8^{a}$ período & $24,42 \%$ \\
\hline Total & $100,00 \%$ \\
\hline
\end{tabular}

Fonte: Dados da Pesquisa (2020) 
Percebe-se que 50,01\% dos respondentes estão cursando do 5ao 8ำ período, ou seja, o curso é bem dividido entre séries iniciais e finais, com destaque para o $8^{\circ}$ período, com $24,42 \%$. Na Tabela 4 , identificouse a ocupação atual dos discentes.

Tabela 4 - Área da Contabilidade que atua

\begin{tabular}{lc}
\hline Área da Contabilidade que atua & Frequência Relativa \\
\hline Controladoria & $2,33 \%$ \\
\hline Auditoria & $2,33 \%$ \\
\hline Gerencial & $0,00 \%$ \\
\hline Fiscal e Tributária & $16,28 \%$ \\
\hline Contábil & $24,42 \%$ \\
\hline Pessoal & $4,65 \%$ \\
\hline Societário & $0,00 \%$ \\
\hline Outro & $1,16 \%$ \\
\hline Não trabalha na área & $48,83 \%$ \\
\hline Total & $\mathbf{1 0 0 , 0 0} \%$ \\
\hline
\end{tabular}

Fonte: Dados da Pesquisa (2020)

Nota-se que $48,83 \%$ dos respondentes ainda não atuam na área, seguidos de $24,42 \%$ que trabalham na área contábil. Importante salientar, ainda, que 16,28\% dos alunos atuam na área fiscal e tributária. Percebe-se que, embora um considerável percentual de respondentes não trabalhe na área, é interessante ressaltar que os mesmos ainda são estudantes, o que pode significar que, em breve, venham a ingressar na área contábil. Em seguida, a Tabela 5 apresenta as percepções dos alunos quanto à profissão contábil, iniciando a segunda etapa de respostas.

Tabela 5 - Percepção dos alunos quanto à profissão

\begin{tabular}{|c|c|c|c|c|c|}
\hline Afirmativa & 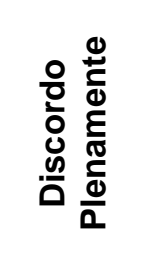 & 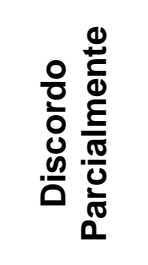 & 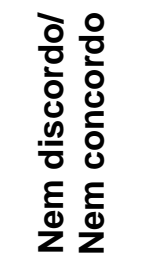 & 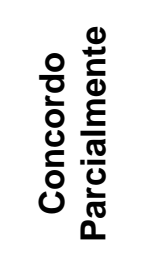 & 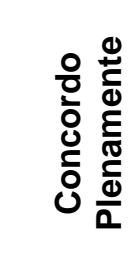 \\
\hline $\begin{array}{l}\text { A profissão contábil é uma profissão que possui } \\
\text { destaque em nossa sociedade, assim como } \\
\text { Direito e Medicina. }\end{array}$ & $13,95 \%$ & $24,43 \%$ & $18,60 \%$ & $29,07 \%$ & $13,95 \%$ \\
\hline $\begin{array}{l}\text { Está mais valorizada, com maiores oportunidades } \\
\text { de trabalho para o Contador. }\end{array}$ & $3,49 \%$ & $12,79 \%$ & $23,25 \%$ & $40,70 \%$ & $19,77 \%$ \\
\hline $\begin{array}{l}\text { Está mais valorizada, entretanto o número de } \\
\text { oportunidade de trabalho continua estável. }\end{array}$ & $6,98 \%$ & $22,09 \%$ & $32,56 \%$ & $30,23 \%$ & $8,14 \%$ \\
\hline $\begin{array}{l}\text { Está mais valorizada, porém o número de } \\
\text { oportunidades de trabalho diminuiu. }\end{array}$ & $25,58 \%$ & $25,58 \%$ & $36,05 \%$ & $11,63 \%$ & $1,16 \%$ \\
\hline $\begin{array}{l}\text { Está menos valorizada e com menor número de } \\
\text { oportunidades de trabalho. }\end{array}$ & $43,02 \%$ & $25,58 \%$ & $23,26 \%$ & $6,98 \%$ & $1,16 \%$ \\
\hline $\begin{array}{l}\text { Está menos valorizada, e o número de } \\
\text { oportunidades de trabalho continua estável. }\end{array}$ & & & $18,60 \%$ & $16,28 \%$ & $2,33 \%$ \\
\hline
\end{tabular}

Fonte: Dados da Pesquisa (2020)

Pode-se observar que $43,02 \%$ dos respondentes concordam, parcial ou plenamente, que a profissão contábil possui destaque na sociedade, assim como Direito e Medicina. Em contrapartida, 38,38\% não concordam com esta afirmação. Esses resultados corroboram com Miranda, Miranda e Araújo (2013) quando $46 \%$ discordam parcial ou plenamente dessa afirmação. Nesse contexto, percebe-se que, embora o objeto do estudo de Miranda, Miranda e Araújo (2013) tenha sido os alunos de ensino médio de todo o Brasil, visualiza-se que não há uma grande variação quando comparado aos alunos de Ciências Contábeis de Santa Catarina, foco deste estudo. Observa-se, também, que $40,70 \%$ dos alunos concordam parcialmente que a profissão está mais valorizada, com maiores oportunidades de trabalho, e somente $3,49 \%$ discordam plenamente dessa ideia. Esses resultados estão de acordo com Machado, Rosa e Martins (2019), quando $31,20 \%$ dos profissionais contábeis de Santa Catarina acreditam que a profissão está mais valorizada, com maiores oportunidades de trabalho para o Contador. Dessa forma, a percepção de profissionais e alunos em 
Santa Catarina é parecida, uma vez que mais da metade dos participantes deste estudo já atua na profissão contábil (Tabela 4), fazendo com que vivenciem o dia a dia da profissão.

Além disso, constata-se que $32,56 \%$ da amostra nem discordam e nem concordam que a profissão contábil está mais valorizada, entretanto o número de oportunidades de trabalho continua estável, enquanto $30,23 \%$ concordam parcialmente. Esses resultados corroboram com Machado, Rosa e Martins (2019), $26,20 \%$ consideram que o número de oportunidades de trabalho continua estável, e a profissão mais valorizada. Pode-se perceber que $51,16 \%$ dos alunos discordam, plenamente ou parcialmente, que a profissão está mais valorizada, porém o número de oportunidades de trabalho diminuiu, além de $36,05 \%$ nem discordar e nem concordar com essa afirmação. Esses resultados vão ao encontro com o de Machado, Rosa e Martins (2019), cujo percentual de 13,1\% de seus respondentes acreditam que o número de oportunidades de trabalho diminuiu e a profissão está mais valorizada. Aqui, pode-se destacar que, tanto os alunos quanto os profissionais contábeis de Santa Catarina, concordam que as oportunidades do mercado de trabalho continuam estáveis e percebem a profissão mais valorizada, mas com um percentual um pouco maior por parte dos acadêmicos. Isso pode ser explicado pelo fato de os profissionais possuírem uma maior experiência e estarem ativos no mercado há mais tempo que os alunos.

Constatou-se que $43,02 \%$ discordam, plenamente, de que a profissão está menos valorizada e com menor número de oportunidades de trabalho, e somente 1,16\% concordam, plenamente, com essa afirmação. Esses resultados não concordam com Machado, Rosa e Martins (2019), 14,5\% concordam que a profissão está menos valorizada e com menor número de oportunidades de trabalho. Percebe-se que $37,21 \%$ dos respondentes discordam plenamente, e $25,58 \%$ discordam, parcialmente, de que a profissão está menos valorizada, e o número de oportunidades de trabalho continua estável. Em contrapartida, 16,28\% concordam, parcialmente, com esta afirmação. Esses resultados corroboram com Machado, Rosa e Martins (2019), quando $15 \%$ afirmam que o número de oportunidades de trabalho continua estável, porém está menos valorizada. No que diz respeito à discordância entre alunos (objeto deste estudo) e profissionais contábeis de Santa Catarina, segundo Machado, Rosa e Martins (2019), pode estar relacionada a uma parte desses Contadores ainda não visualizarem uma valorização da profissão, enquanto que, para os estudantes, isso pode ser algo discutido com frequência no curso.

Analisando estes resultados, o que se observa, de maneira geral, é que quase metade dos alunos da IES de Santa Catarina concorda que a profissão contábil possui uma considerável valorização em relação às profissões mais tradicionais, como Direito e Medicina. Além disso, os alunos concordam que a profissão está mais valorizada, com maiores oportunidades de trabalho, sendo favorável para os ingressantes do curso, pois, em breve, exercerão a profissão com muitas oportunidades de trabalho. A Tabela 6 inicia a terceira etapa de resultados ao evidenciar a percepção dos alunos quanto à valorização e ao reconhecimento do profissional contábil.

Tabela 6 - Percepção dos alunos quanto à valorização e reconhecimento do profissional contábil

Afirmativa

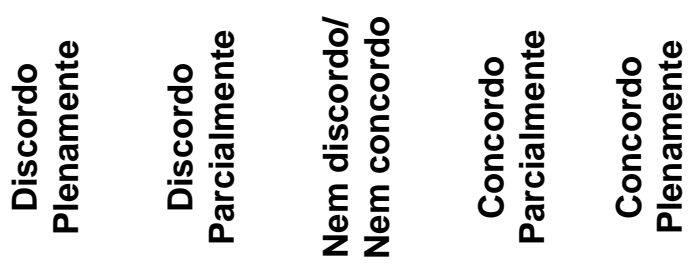

O profissional contábil prova a sua importância e relevância para a sociedade não apenas pela profissão que exerce, mas também pelo exemplo de $0,00 \% \quad 2,33 \% \quad 9,30 \% \quad 31,39 \% \quad 56,98 \%$ profissionalismo e de conduta.

Existe crescimento do mercado de trabalho para o profissional contábil.

O profissional contábil evoluiu ao longo do tempo.

O profissional contábil possui facilidade de encontrar emprego.

O profissional contábil possui salário alto.

O profissional contábil possui

responsabilidade na empresa.

possui grande

Fonte: Dados da Pesquisa (2020)

A grande maioria dos alunos (88,37\%) concorda, parcial ou plenamente, que o profissional contábil prova a sua importância e relevância para a sociedade, não apenas pela profissão que exerce, mas também pelo exemplo de profissionalismo e de conduta, sendo um ponto positivo para o profissional contábil. Esses 
resultados corroboram com Cavalcante (2012) quando 97\% acreditam nessa afirmação. Além disso, a maior parte da amostra $(82,56 \%)$ respondeu que concorda, parcial ou plenamente, que existe crescimento do mercado de trabalho para o profissional contábil, sendo que somente $3,49 \%$ não concordam com a afirmação. Esses resultados estão de acordo com Cavalcante (2012), 82\% afirmam que existe crescimento do mercado de trabalho para o profissional contábil. Aqui, percebe-se a concordância entre os alunos desta pesquisa e os estudantes do curso de Ciências Contábeis do extremo oeste de Santa Catarina, do estudo de Cavalcante (2012). Nesse contexto, verifica-se que os acadêmicos de Ciências Contábeis de Santa Catarina possuem uma visão parecida no que diz respeito ao profissional contábil.

Grande parte dos respondentes, ou seja, 94,19\% concordam, parcial ou plenamente, que o profissional contábil evoluiu ao longo do tempo, sendo que, apenas, 5,81\% nem discordam e nem concordam com esta afirmação. Esses resultados vão ao encontro de Moraes e Martins (2018), os quais mostram que 70,18\% concordam que o profissional contábil evoluiu ao longo do tempo. Dessa forma, embora os resultados sigam na mesma direção, o estudo de Moraes e Martins (2018) apresenta um percentual menor quando comparado ao deste estudo; e isso pode ser explicado pelo fato de o objeto de pesquisa desses autores ser acadêmico de Administração em Santa Catarina. Além disso, 70,93\% dos discentes concordam, parcial ou plenamente, que o profissional contábil possui facilidade de encontrar emprego. Esses resultados corroboram com Cavalcante (2012) quando 80\% concordam com essa afirmação. Já neste achado, percebe-se a proximidade de frequência por se tratar de alunos do mesmo curso.

Observa-se que $50,01 \%$ dos alunos discordam que o profissional contábil possui salário alto, sendo que $33,73 \%$ discordam parcialmente, e 16,28\% discordam, plenamente, dessa afirmação. Esses resultados não corroboram com Cavalcante (2012) quando mostra que $66 \%$ concordam que o profissional contábil possui salário alto. Ainda assim, pode-se perceber que quase toda amostra $(98,84 \%)$ concorda, parcial ou plenamente, que o Contador possui grande responsabilidade na empresa, em contrapartida, somente 1,16\% nem concorda e nem discorda dessa informação. Esses resultados estão de acordo com Cavalcante (2012), $97 \%$ concordam que o Contador possui grande responsabilidade na empresa. Embora os resultados se assemelhem quanto ao Contador possuir grande responsabilidade na empresa, os estudantes discordam sobre este profissional possuir salário alto. Isso pode ser explicado pelo fato de a pesquisa de Cavalcante ter ocorrido em 2012 e, nesse tempo, os rendimentos do profissional contábil não terem acompanhado uma possível valorização da profissão.

Nesse contexto, pode-se perceber que o profissional contábil de Santa Catarina evoluiu ao longo do tempo. Além disso, o mesmo possui facilidade de encontrar emprego, visto que as oportunidades de trabalhos são amplas. O Contador detém grandes responsabilidades dentro da empresa, ou seja, ele é uma peça fundamental para que a entidade cresça de maneira estruturada, assim, este profissional tende a ser cada vez mais valorizado, já que as empresas necessitam, cada vez mais, dos serviços prestados pelos mesmos. A Tabela 7 mostra as exigências do mercado de trabalho para os profissionais contábeis, com a última etapa dos dados.

Tabela 7 - Exigências do mercado de trabalho para profissionais contábeis

\begin{tabular}{|c|c|c|c|c|c|}
\hline Afirmativa & 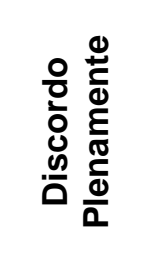 & 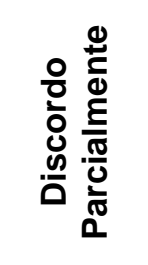 & 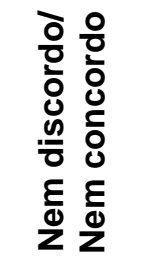 & 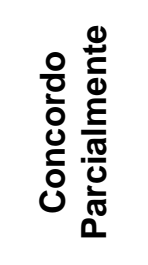 & 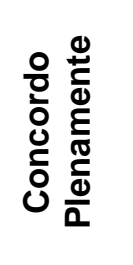 \\
\hline $\begin{array}{l}\text { Valoriza muito os serviços prestados por esse } \\
\text { profissional. }\end{array}$ & $3,49 \%$ & $20,93 \%$ & $22,09 \%$ & $32,56 \%$ & $20,93 \%$ \\
\hline Desvaloriza seus serviços prestados. & $27,91 \%$ & $30,23 \%$ & $29,07 \%$ & $11,63 \%$ & $1,16 \%$ \\
\hline Desvaloriza, mas necessita muito dos serviços. & & & & & \\
\hline Não é valorizado, pois seu público é muito crítico. & & & & & \\
\hline $\begin{array}{l}\text { Como profissional de uma maneira geral, ganha } \\
\text { pouco. }\end{array}$ & $5,81 \%$ & $6,98 \%$ & $27,91 \%$ & $46,51 \%$ & $12,79 \%$ \\
\hline $\begin{array}{l}\text { Encontra emprego mais facilmente em grandes } \\
\text { empresas. }\end{array}$ & $5,81 \%$ & $20,93 \%$ & $27,91 \%$ & $33,72 \%$ & $11,63 \%$ \\
\hline O curso de Ciências Contábeis forma profissionais & $1,16 \%$ & $6,98 \%$ & $22,09 \%$ & $50,00 \%$ & $19,77 \%$ \\
\hline $\begin{array}{l}\text { Tem menores oportunidades de trabalho do que } \\
\text { aqueles que fazem graduação em Administração. }\end{array}$ & $51,16 \%$ & $23,26 \%$ & $17,44 \%$ & $6,98 \%$ & $1,16 \%$ \\
\hline
\end{tabular}

Fonte: Dados da Pesquisa (2020) 
Nota-se que $32,56 \%$ dos respondentes concordam, parcialmente, que o mercado de trabalho de Santa Catarina valoriza muito os serviços prestados por este profissional, e 20,93\% discordam, parcialmente, dessa afirmação. Estes resultados não corroboram com Machado, Rosa e Martins (2019), somente 11,5\% concordam que o mercado de trabalho valoriza muito os serviços prestados por este profissional. Observa-se que a maioria dos respondentes $(58,14 \%)$ discorda, parcial ou plenamente, que o mercado de trabalho desvaloriza seus serviços prestados, sendo que, apenas, $11,63 \%$ concordam parcialmente, com esta afirmação. Esses resultados vão ao encontro de Machado, Rosa e Martins (2019) quando apenas 8,1\% concordaram que o mercado de trabalho desvaloriza seus serviços prestados. Cabe destacar que, embora alunos e profissionais contábeis do estudo de Machado, Rosa e Martins (2019) não acreditem que o mercado de trabalho desvaloriza os serviços prestados pela contabilidade, não chegam a um consenso em relação à valorização desses serviços. O percentual mais baixo atribuído pelos profissionais pode ser explicado pelo fato de vivenciarem a profissão há mais tempo que os alunos, podendo compreender, com mais clareza, o mercado de trabalho contábil.

Pode-se perceber que mais da metade dos alunos $(53,49 \%)$ concorda, parcial ou plenamente, que o mercado de trabalho desvaloriza, porém, necessita muito dos serviços. Esses resultados corroboram com Machado, Rosa e Martins (2019) quando 74,6\% acreditam que o mercado de trabalho desvaloriza, porém necessita muito dos serviços. A frequência maior, por parte dos profissionais, pode estar relacionada ao parágrafo anterior quando afirmaram que os serviços prestados não são valorizados. Além disso, percebe-se que $40,70 \%$ dos discentes não concordam, parcial ou plenamente, ao dizer que o mercado de trabalho não é valorizado, pois seu público é muito crítico. Em contrapartida, 39,53\% nem concordam e nem discordam dessa afirmação, podendo ser explicado pelo fato de que os respondentes não tenham compreendido a pergunta, pois grande parte da amostra não trabalha na área. Esses resultados não estão de acordo com Machado, Rosa e Martins (2019), apresentando somente 5,8\% que concordam que o mercado de trabalho não é valorizado, pois seu público é muito crítico.

Constatou-se que $59,30 \%$ da amostra concordam, parcial ou plenamente, que o profissional, de uma maneira geral, ganho pouco. Esses resultados discordam com Miranda, Miranda e Araújo (2013), somente $31,30 \%$ corroboram com essa afirmação. Além disso, $45,35 \%$ dos alunos concordam, parcial ou plenamente, que o profissional consegue encontrar emprego mais facilmente em grandes empresas. Por outro lado, $26,74 \%$ não concordam com essa afirmação. Esses resultados confirmam os de Miranda, Miranda e Araújo (2013) quando 51,7\% acreditam que o profissional consegue encontrar emprego mais facilmente em grandes empresas. Embora os estudantes concordem que os profissionais contábeis consigam se colocar no mercado de maneira mais rápida, discordam no que diz respeito ao Contador ganhar pouco. Isso pode estar relacionado ao fato de os alunos da pesquisa de Miranda, Miranda e Araújo (2013) ainda estarem no ensino médio. Dessa forma, muitos deles sequer conhecem a profissão contábil ou compreendem como está direcionado o mercado de trabalho para esses profissionais.

Observa-se que a maioria dos alunos $(69,77 \%)$ acredita, parcial ou plenamente, que o curso de Ciências Contábeis forma profissionais que encontram boas oportunidades de empregos e somente 8,14\% não concordam com essa afirmação. A questão aplicada poderá funcionar como estímulo para os estudantes matriculados e, também, para os futuros estudantes do curso. Esses resultados vão ao encontro do estudo de Miranda, Miranda e Araújo (2013), em que 71,70\% concordam que o curso de Ciências Contábeis forma profissionais que encontram boas oportunidades de empregos. Por fim, é possível verificar que $74,42 \%$ da amostra não concordam que o profissional possui menores oportunidades de trabalho do que aqueles que fazem graduação em Administração, sendo que, apenas, 8,14\% concordam com essa afirmação. Esse achado corrobora com Miranda, Miranda e Araújo (2013), quando somente 35\% discordam que o profissional tem menores oportunidades de trabalho do que aqueles que fazem graduação em Administração. Já para este achado, a diferença de percentual, também, pode estar relacionada ao fato de os participantes do estudo de Miranda, Miranda e Araújo (2013) ainda serem estudantes do ensino médio e não possuírem conhecimento específico do mercado de trabalho, tanto contábil quanto relacionado ao curso de Administração.

Desse modo, percebe-se que os alunos de Santa Catarina compreendem a valorização do mercado de trabalho em relação aos serviços prestados pelo profissional contábil, embora acreditem que o Contador ganhe pouco. Por outro lado, também concordam que o mesmo pode encontrar emprego facilmente, que pode ser explicado pelo fato de este profissional poder atuar em várias áreas da profissão.

\section{CONSIDERAÇÕES FINAIS}

O presente artigo buscou analisar a percepção de alunos de graduação em Ciências Contábeis de uma universidade comunitária de Santa Catarina acerca da valorização e do reconhecimento do profissional contábil. Desse modo, com base na análise realizada, concluiu-se que os discentes de Ciências Contábeis da IES de Santa Catarina possuem uma boa percepção sobre o profissional contábil, pois reconhecem sua importância para a sociedade. 
A contabilidade possui uma considerável valorização em relação às profissões mais tradicionais, como Direito e Medicina. Além disso, os alunos concordam que a profissão está mais valorizada, com maiores oportunidades de trabalho, sendo favorável para os ingressantes do curso, pois, em breve, exercerão a profissão. Dessa forma, eles concordam que a profissão está mais valorizada e com maiores oportunidades de trabalho, entretanto quase metade dos alunos não trabalha na área, isso pode ser explicado pelo fato de estarem cursando as primeiras fases do curso.

Com base no estudo realizado, ressalta-se que o profissional contábil evoluiu ao longo do tempo e possui facilidade de encontrar emprego, visto que as oportunidades de trabalhos são amplas, e a mesma prova sua importância e relevância para a sociedade, não apenas pela profissão que exerce, mas também pelo exemplo de profissionalismo e de conduta, sendo um ponto positivo para os discentes de Ciências Contábeis que, em breve, estarão trabalhando ou que já trabalham nesta área.

O profissional contábil está sendo valorizado em relação às responsabilidades e aos procedimentos que exerce, porém, financeiramente, ainda não. Desse modo, percebe-se que os alunos compreendem a valorização do mercado de trabalho em Santa Catarina em relação aos serviços prestados pelo profissional contábil, porém acreditam que o mesmo ganhe pouco. Por meio da pesquisa, pode-se observar que são poucos os alunos que trabalham na área contábil. Sendo assim, este é um cenário preocupante, pois existe um número considerável da amostra que é do último período do curso. É indispensável que seja revelado, cada vez mais, a importância do trabalho do profissional da contabilidade, para que, assim, seja mais reconhecido, e, assim, surjam mais oportunidades de trabalho. É importante ressaltar que os discentes de Ciências Contábeis não concordam que possuem menos oportunidades de trabalho do que aqueles que fazem graduação em Administração, por exemplo.

Fica evidente que o Contador possui grandes responsabilidades dentro da empresa e que o mercado de trabalho, na região da IES pesquisada, compreende a necessidade deste profissional e o quanto o seu desempenho exerce influência no desenvolvimento e no aumento das organizações. Cabe destacar a importância desta pesquisa para os profissionais contábeis que, em conjunto com a sua função para a sociedade, pode servir de estímulo para os futuros profissionais, visto que há uma longa estrada a se percorrer sobre 0 assunto.

Ressalta-se que foi possível responder, satisfatoriamente, à pergunta de pesquisa, sendo que o objetivo foi alcançado e os procedimentos metodológicos utilizados foram adequados. Como contribuições, este artigo auxiliou os acadêmicos a construírem uma melhor visão no que diz respeito à profissão contábil. Além disso, este estudo buscou contribuir com os profissionais contábeis, com o intuito de serem cada vez mais valorizados e reconhecidos pela atividade que exercem. Tratando-se, especificamente, do mercado de trabalho contábil em Santa Catarina, este artigo pode contribuir para uma melhor compreensão e visibilidade da profissão contábil e, por consequência, uma maior valorização e reconhecimento para os profissionais.

Em relação às limitações da pesquisa, este estudo não pode ser generalizado, visto que a amostra corresponde a somente um curso de Ciências Contábeis da universidade em análise. Sugere-se, para estudos futuros, a realização de pesquisas para verificar a importância dos serviços prestados pelos profissionais contábeis na percepção de empresários e comparar com a visão dos próprios profissionais e/ou alunos. Recomenda-se, também, analisar o valor dos profissionais contábeis para as entidades. Por fim, propõe-se uma pesquisa qualitativa para compreender a valorização que tanto alunos como empresários atribuem aos profissionais contábeis.

\section{REFERÊNCIAS}

ALMEIDA, G. T.; MEDEIROS, L. M. Percepções em relação ao profissional contábil: Investigação comparativa com estudantes ingressantes e concluintes. Revista de Contabilidade do Mestrado em Ciências Contábeis da UERJ, v. 22, n. 1, p. 104-121, 2017.

AYRES, R. M.; NASCIMENTO, J. C. H. B.; MACEDO, M. A. S. Satisfação do profissional de contabilidade do estado do Rio de Janeiro quanto à qualidade de vida no trabalho-QVT (2014-2015): Uma análise por PLS-SEM com base no modelo dimensional de Walton. Pensar Contábil, v. 18, n. 67, p. 5-14, 2017.

CAVALCANTE, C. H. L. Percepção dos alunos iniciantes e concluintes do curso de Ciências Contábeis sobre a profissão contábil. Revista Brasileira de Contabilidade, v. 1, n. 177, p. 50-63, 2012.

CERNUSCA, L.; BALACIU, D. E. The perception of the accounting students on the image of the accountant and the accounting profession. Journal of Economics and Business Research, v. 21, n. 1, p. 7-24, 2015.

CUNHA, A.; OLIVIO, A.; MARTINS, Z. B. Percepção de clientes acerca do grau de importância e nível de satisfação com os serviços prestados pelo profissional da contabilidade. Revista Brasileira de Contabilidade, v. 1, n. 227, p. 70-81, 2017.

FAHL, A. C.; MANHANI, L. P. S. As perspectivas do profissional contábil e o ensino da contabilidade. Revista de Ciências Gerenciais, v. 10, n. 12, p. 25-33, 2015. 
FARBER, J. C.; LUZ, M. F.; QUEIROZ, F. C.; MUNHOZ, W. A.; LIMA, M. A percepção dos alunos iniciantes e concluintes do curso de Ciências Contábeis sobre a profissão contábil. Revista Ampla de Gestão Empresarial, v. 3, n. 1, p. 139161, 2014.

FEIL, A. Análise das variáveis intervenientes na tomada de decisão ética do Profissional Contábil. Enfoque Reflexão Contábil, v. 35, n. 1, p. 75-93, 2016.

FRANCO, I. F. S.; DIAS, L. P.; CARDOSO, R.; BELOUMINI, J. A visão dos contabilistas sobre a valorização e o reconhecimento do profissional. Revista de Auditoria Governança e Contabilidade, v. 6, n. 25, p. 132-147, 2018.

KING, D. L.; CASE, C. J.; SENECKER, K. M. Accounting history in perspective: Uniform CPA exam turns 100. Journal of Business and Behavioral Sciences, v. 29, n. 2, p. 70-84, 2017.

MACHADO, D.; ROSA, T.; MARTINS, Z. B. O mercado de trabalho na percepção dos profissionais contábeis. Revista de Contabilidade da UFBA, v. 13, n. 1, p. 84-104, 2019.

MARIN, A. M. The image of the accounting professional in the activity of an economic entity. Academic Journal, v. $25, \mathrm{n}$. 6, p. 147-152, 2018.

MENDONÇA, W. S.; MARTINS, V. F. Análise do cumprimento do programa de Educação Profissional Continuada aplicada aos auditores independentes. Revista de Auditoria, Governança e Contabilidade, v. 8, n. 36, p. 1-14, 2020.

MIRANDA C. S.; MIRANDA R. A. M.; ARAÚJO, A. M. P. Percepções dos estudantes do ensino médio sobre o curso de Ciências Contábeis e as atividades do profissional contador. Revista de Gestão, Finanças e Contabilidade, v. 3, n. 1, p. 17-35, 2013.

MIRANDA, V. L.; FARIA, J. A. Caricaturas e estereótipos do contador: Como a imagem do profissional de contabilidade vem sendo veiculada em um jornal de grande circulação no Brasil?. Revista de Administração, Contabilidade e Economia, v. 15, n. 3, p. 1087-1116, 2016.

MORAES, L. C.; MARTINS, Z. B. A percepção dos discentes de Administração acerca dos profissionais contábeis. Revista Conhecimento Contábil, v. 7, n. 2, p. 2447-2921, 2018.

MORAIS, M. L. S.; MARTINS, Z. B.; ALBERTON, L. Percepção dos auditores independentes quanto à efetividade da capacitação realizada para o cumprimento da Norma Brasileira de Contabilidade de Educação Profissional Continuada. Pensar Contábil, v. 19, n. 69, p. 4-17, 2017.

PARKER, L. D.; WARREN, S. The presentation of the self and professional identity: Countering the accountant's stereotype. Accounting, Auditing \& Accountability Journal, v. 30, n. 8, p. 1895-1924, 2017.

PAULA, E. A importância da ciência contábil e a valorização do profissional contábil nas entidades públicas. Sinergia, v. 17, n. 2, p. 151-155, 2016

PRODANOV, C. C.; FREITAS, E. C. Metodologia do trabalho científico: Métodos e técnicas da pesquisa e do trabalho acadêmico. 2 ed. Novo Hamburgo: Feevale, 2013.

RAFFAELLI, S. C. D.; ESPEJO, M. M. S. B.; PORTULHAK, H. A imagem do profissional contábil: Análise da percepção socialmente construída por estudantes de Ciências Econômicas. Revista Contemporânea de Contabilidade, v. 13, n. 29, p. 157-178, 2016.

REIS, A. O.; SEDIYAMA, G. A. S.; MOREIRA, V. S.; MOREIRA, C. C. Perfil do profissional contábil: Habilidades, competências e imagem simbólica. Revista contemporânea de Contabilidade, v. 12, n. 25, p. 95-116, 2015.

RICHARDSON, R. J. Pesquisa social: Métodos e técnicas. 4 ed. São Paulo: Atlas, 2017.

RODRIGUES, A. J.; GONÇALVES, H. A.; MENEZES, M. B. C.; NASCIMENTO, M. F. Metodologia científica. Aracaju: UNIT, 2014.

SILVA, A. C. R. Metodologia da pesquisa aplicada à Contabilidade. Salvador: UFBA, 2017.

SILVA, B. N.; SANTANA, C. L.; MEIRELLES JÚNIOR, J. C. Formação acadêmica em Ciências Contábeis e sua relação com o mercado de trabalho: A percepção de formandos de Ciências Contábeis de uma instituição de ensino superior. Revista Brasileira de Contabilidade, v. 1, n. 225, p. 66-77, 2017.

VIRTUOSO, G. C. P.; MARTINS, Z. B. Perception of business people on the evolution of the accountant profile. Research, Society and Development, v. 7, n. 4, p. 1-18, 2018. 
